\title{
Inhibitory effects of saturated fatty acids on methane production by methanogenic Archaea
}

\author{
J.O. Zeitz ${ }^{1,4}$, S. Bucher ${ }^{1}$, X. Zhou ${ }^{1}$, L. Meile ${ }^{2}$, M. Kreuzer ${ }^{1}$ and C.R. Soliva ${ }^{1,3}$ \\ ${ }^{1}$ ETH Zurich, Institute of Agricultural Sciences, Universitaetstrasse 2, 8092 Zurich, Switzerland \\ ${ }^{2}$ ETH Zurich, Institute of Food, Nutrition and Health, Schmelzbergstr. 7, 8092 Zurich, Switzerland \\ ${ }^{3}$ Current address: University of Zurich, Institute of Animal Nutrition, \\ Winterthurerstrasse 260, 8057 Zurich, Switzerland
}

KEY WORDS: methanogen, methane, saturated fatty acid, lipid, inhibition
Received 19 September 2012

Revised 15 January 2013

Accepted 21 March 2013

${ }^{4}$ Corresponding author: e-mail: jzeitz@gmx.de

\begin{abstract}
The present study investigated the inhibitory effects of saturated fatty acids on methanogenesis in Archaea, and whether or not competitive inactivation of the methanogens' coenzyme M (HS-CoM) is involved in the inhibition. Strains tested in batch cultures were Methanosarcina barkeri, Methanosarcina mazei, Methanococcus voltae, all incubated at $37^{\circ} \mathrm{C}$, and Methanothermobacter thermoautotrophicus, incubated at $65^{\circ} \mathrm{C}$. The fatty acids $\mathrm{C}_{10}, \mathrm{C}_{12}, \mathrm{C}_{14}$ and $\mathrm{C}_{18}$ were supplemented at $1 \mathrm{mg} \cdot \mathrm{ml}^{-1}$ in cultivation medium. The methanogens were susceptible to $C_{10}$ and $C_{12}$, and less so to $C_{14}$. Only M. thermoautotrophicus was affected by $C_{18}$. In $M$. mazei cultures, excessive HS-CoM did not prevent the action of $\mathrm{C}_{14}$ which might suggest that competitive inhibition of HS-CoM is not the reason for the SFA-induced effect on methanogenesis. The results indicate that, as a prerequisite to inhibit methanogenesis in Archaea, medium- and long-chain saturated fatty acids have to be at least partially molten.
\end{abstract}

\section{Introduction}

The Archaea colonizing the rumen have attracted attention as they form the greenhouse gas methane $\left(\mathrm{CH}_{4}\right)$ thus contributing to global warming (Hook et al., 2010). Dietary fats rich in saturated mediumchain length fatty acids (MCFA) have been shown to suppress $\mathrm{CH}_{4}$ formation in vivo (Machmüller and Kreuzer, 1999). At $39^{\circ} \mathrm{C}$, lauric $\left(\mathrm{C}_{12}\right)$ and myristic acid $\left(\mathrm{C}_{14}\right)$, two MCFA, are anti-methanogenic both in ruminal fluid (Dohme et al., 2001) and in sludge (Koster and Cramer, 1987), while saturated fattyacids (SFA) of longer-chain length such as palmitic acid $\left(\mathrm{C}_{16}\right)$ and stearic acid $\left(\mathrm{C}_{18}\right)$ did not exert this effect in vitro (Dohme et al., 2001; Soliva et al.,
2004; Zhang et al., 2008) and in vivo (Hristov et al., 2009). However, findings are not always consistent, e.g. $\mathrm{C}_{12}$ and $\mathrm{C}_{14}$ do not necessarily inhibit $\mathrm{C}_{14}$ emissions in vivo (Hristov et al., 2009, 2011). Effective inhibition of ruminal methanogenesis by SFA requires knowledge about factors influencing the efficiency of $\mathrm{CH}_{4}$ mitigation and the underlying modes of action. In the present study, as a first hypothesis it was tested whether the anti-methanogenic effect of SFA in methanogenic Archaea is affected either by SFA chain length, which is related to SFA melting temperature, or by cultivation temperature or both; a thermophilic methanogen species was employed for investigations at high cultivation temperature. To effectively target all methanogens, $\mathrm{CH}_{4}$ suppres- 
sors have to affect cell structures or metabolic functions common to all methanogens, although methanogens differ in composition and structure of their cell envelopes (Albers and Meyer, 2011) as well as utilize different substrates, metabolic pathways and enzymes (Thauer et al., 2008). The second hypothesis tested was, therefore, that SFA act anti-methanogenic in methanogenic Archaea independent of the metabolic pathway used to form $\mathrm{CH}_{4}$. For that purpose, Methanosarcina mazei, able to grow without $\mathrm{H}_{2}$ and $\mathrm{CO}_{2}$ as substrates (Hovey et al., 2005), was cultivated on methanol to test whether this methanogenic pathway is also inhibited. A key coenzyme for any kind of methanogenesis and thus common to all methanogenic Archaea is the methyl-coenzyme $\mathrm{M}$ reductase (MCR) (Thauer, 1998). The genes encoding MCR are expressed to the same level irrespective if $M$. mazei forms $\mathrm{CH}_{4}$ from acetate or from methanol even though numerous, mainly methanol-pathways specific, genes show different expression levels in the cells grown on methanol as compared to the cells grown on acetate (Hovey et al., 2005). This enzyme is involved in the release of $\mathrm{CH}_{4}$ from methyl-coenzyme $\mathrm{M}$ by formation of a heterodisulfide of 2-mercaptoethanesulfonic acid (HS-CoM), i.e. coenzyme M, and coenzyme B (Thauer, 1998). The SFA have a certain structural similarity to coenzymes $\mathrm{M}$ and $\mathrm{B}$ thus maybe acting as competitors for the position in the hydrophobic channel of the MCR. If this were true, an excess of HS-CoM would actively counteract this competition. The third hypothesis tested was therefore that the anti-methanogenic action of SFA is mediated through competition with coenzyme M, thus inactivating MCR (Thauer, 1998) and, in consequence, $\mathrm{CH}_{4}$ formation.

\section{Material and methods}

\section{Experimental microbes and cultivation}

All methanogenic strains investigated were obtained as live cultures from DSMZ (www.dsmz. de) delivered in cultivation media. Methanosarcina barkeri DSM 800 and M. mazei DSM 7222 were both isolated from an anaerobic sewage digester, and Methanococcus voltae DSM 1537 was isolated from mud. All had a temperature optimum between 35 to $37^{\circ} \mathrm{C}$ and were cultivated at $37^{\circ} \mathrm{C}$. The thermophilic strain Methanothermobacter thermoautotrophicus DSM 1053, isolated from sewage sludge with a temperature optimum of 55 to $70^{\circ} \mathrm{C}$ was cultivated at $65^{\circ} \mathrm{C}$. The intention for selecting these strains was to include non-thermophilic strains representing four different methanogenic orders to get an overview if the anti-methanogenic effect of SFA might occur in all methanogens. Cultures of $M$. barkeri and M. mazei were shaken with a Kühnershaker Labtherm (Adolf Kühner AG, Birsfelden, Switzerland) at $80 \mathrm{rpm}$ during cultivation. Anaerobic cultivation was performed in 120-ml cultivation flasks containing $30 \mathrm{ml}$ of the respective, strain-specific cultivation media as described by DSMZ. Different from the DSMZ protocols, Na-EDTA $\left(14.2 \mu \mathrm{mol} \cdot 1^{-1}\right)$ instead of nitrilotriacetate was used for the cultivation medium of $M$. voltae. Ruminal fluid from a rumencannulated cow was clarified by filtering through four layers of medicinal gauze and subsequent centrifugation for $15 \mathrm{~min}$ at $4000 \mathrm{~g}$ (Varifuge $\mathbb{R}$ K, Heraeus, Osterode, Germany). Then the supernatant was filtered five times using filters with pore sizes of $20,2.5,<2.0,<0.7$, and $0.2 \mu \mathrm{m}$. Heat stable solutions of other media ingredients were sterilized in a batch autoclave (Sauter, Belimed Sauter AG, Sulgen, Switzerland) for $20 \mathrm{~min}$ at $121^{\circ} \mathrm{C}$. Heat susceptible solutions were filtered through a $0.2 \mu \mathrm{m}$ Minisart-plus filter (Sartorius AG, Göttingen, Germany) and a vacuum-sterile filter (VWR $250 \mathrm{ml}$ system capacity, $0.2 \mu \mathrm{m}$ pore size, VWR International AG, Dietikon, Switzerland). Media reagents were prepared in an anaerobic chamber using boiled oxygen-deprived distilled water (Coy Laboratory Products, Grasslake, USA).

Culture development was monitored by analyzing $\mathrm{CH}_{4}$ formation. This variable had been found to vary in parallel to changes in optical density, i.e. growth, in own preceding investigations. Before the start of the experiment, 20 to $50 \mu \mathrm{l} . \mathrm{ml}^{-1}$ of previously established cultures - from now on named 'pre-cultures' - were used to inoculate fresh medium when $\mathrm{CH}_{4}$ formation was in the mid-exponential phase.

The SFA tested were $\mathrm{C}_{10}, \mathrm{C}_{12}, \mathrm{C}_{14}$ and $\mathrm{C}_{18}$, each of a purity of at least $97 \%$ (Fluka Chemie AG, Buchs, Switzerland). Concentrated SFA stock solutions (30 $\mathrm{mg} \cdot \mathrm{ml}^{-1}$ ) were prepared without solvent with cultivation medium alone, autoclaved, and stored at $65^{\circ} \mathrm{C}$ before being added to the methanogen cultures. The dosage selected was $1 \mathrm{mg} \cdot \mathrm{ml}^{-1}$ cultivation medium as this was equivalent to the level that proved effective in a previous in vitro experiment with bovine ruminal fluid (Soliva et al., 2003). The sodium 2-mercaptoethanesulfonate (HS-CoM) was obtained from Sigma-Aldrich (BioXtra, Buchs, Switzerland) with $\geq 98.0 \%$ purity.

\section{Experiment 1}

The experimental cultures were initiated with concentrations of 28,17 and $50 \mu \mathrm{l} \cdot \mathrm{ml}^{-1}$ of pre-cultures of $M$. barkeri, $M$. voltae and $M$. thermoautotrophicus, respectively, with preculture optical densities, measured at $600 \mathrm{~nm}$, of $0.77,0.86$ and 0.11 , respectively, under a $80 \%$ 
$\mathrm{H}_{2}: 20 \% \mathrm{CO}_{2}$ atmosphere (Pangas AG, Dagmarsellen, Switzerland) and an initial headspace gas pressure of 200 to $250 \mathrm{kPa}$. The gas mixture in the headspace was renewed every $24 \mathrm{~h}$. The SFA were supplemented to the respective cultures when methanogens had reached the mid-exponential phase. $M$. barkeri was exposed to $\mathrm{C}_{12}$ and $\mathrm{C}_{14}, M$. voltae to $\mathrm{C}_{10}$, $\mathrm{C}_{14}$ and $\mathrm{C}_{18}$, and $M$. thermoautotrophicus to $\mathrm{C}_{12}, \mathrm{C}_{14}$ and $\mathrm{C}_{18}$. This approach accounted for the limitation in numbers of incubation bottles to be handled while still having always one reference fatty acid $\left(\mathrm{C}_{14}\right)$. After adding SFA, $\mathrm{CH}_{4}$ formation was measured for at least $24 \mathrm{~h}$. Cultivations were performed in triplicate. Control cultures consisted of the respective methanogenic strains without exposure to SFA. Subsequently, it was tested whether the SFA-effects exhibited on the strains were reversible. For that purpose, 28, 17 and $50 \mu \mathrm{l} \cdot \mathrm{ml}^{-1}$ of the experimental and control cultures, were taken $24 \mathrm{~h}$ after the exposure to SFA and cultivated in fresh medium without adding SFA.

\section{Experiment 2}

In the second experiment, M. mazei was grown in triplicate in $\mathrm{N}_{2}$ atmosphere under a headspace gas pressure of $100 \mathrm{kPa}$ on methanol $\left(0.25 \mathrm{~mol} \cdot 1^{-1}\right.$ medium $)$ as sole substrate for methanogenesis. $17 \mu \mathrm{l} \cdot \mathrm{ml}^{-1}$ of pre-culture in the midexponential phase was used for inoculation. For comparative reasons, $\mathrm{C}_{14}$ was chosen as this was the only SFA used with each of the strains investigated in Experiment 1. The cultures were exposed to $1 \mathrm{mg} \mathrm{C}_{14} \cdot \mathrm{ml}^{-1}$ medium. Additionally, either 0 or $1.4 \mathrm{mg}$ of $\mathrm{HS}-\mathrm{CoM} \cdot \mathrm{ml}^{-1}$ was supplemented to the incubation flasks. This is equivalent to a ratio of 1 mol $_{14}: 2$ mol HS-CoM, which was higher than what is required according to stoichiometric calculations by the methanogens to form the amount of $\mathrm{CH}_{4}$ measured in pre-cultures and therefore, assumed to be available in excessive amounts.

\section{Laboratory and statistical analysis}

The gas volume produced in the batch cultures was calculated from headspace volume, overpressure (measured by the manometer GDH 200-13, Greisinger Electronic GmbH, Regenstauf, Germany), and temperature applying the law of the ideal gas. A volume of $0.15 \mathrm{ml}$ gas was collected from the headspace of the cultivation flasks and analyzed for its $\mathrm{CH}_{4}$ concentration using a gas chromatograph (model 6890N, Agilent Technologies, Santa Clara, CA, USA) equipped with a flame ionization detector and a $234 \mathrm{~mm} \times 23 \mathrm{~mm}$ column $(80 / 100$; 166 mesh; Porapak Q, Fluka Chemie AG, Buchs,
Switzerland). Methane formation rate was calculated from gas volume produced and changes occurring in $\mathrm{CH}_{4}$ concentration in the meantime between two measurement points.

Analysis of variance was performed using the MIXED procedure of SAS (version 9.1 of 2003; SAS Institute Inc., Cary, NC) with the repeated statement to compare control and SFA-supplemented cultures at each measurement point. Multiple comparisons were done using Tukey's procedure. In order to evaluate the reversibility of SFA-inhibited cultures at each measuring point, the TTEST procedure of SAS was used. In order to evaluate whether the culture $\mathrm{CH}_{4}$ formation was different from zero, the one-sample ttest was applied. For pairwise comparisons between those treatment groups where a certain culture recovery occurred the two-sample t-test was used. Differences were declared significant at $\mathrm{P}<0.05$.

\section{Results}

\section{Experiment 1}

The $\mathrm{CH}_{4}$ formation by $M$. barkeri was significantly decreased by $90 \%$ within $12 \mathrm{~h}$ and ceased after $18 \mathrm{~h}$ subsequent to adding $\mathrm{C}_{12}$ (Figure 1, top). No $\mathrm{CH}_{4}$ formation was detected after transferring $\mathrm{C}_{12}$-inhibited M. barkeri to new, $\mathrm{C}_{12}$-free medium. With $\mathrm{C}_{14}, 18 \mathrm{~h}$ after addition, $\mathrm{CH}_{4}$ formation rate was significantly decreased by $47 \%$ compared to that of the control. In the reversibility period, $\mathrm{CH}_{4}$ formation of previously $\mathrm{C}_{14}$-treated cultures was retarded by about 6 to $12 \mathrm{~h}$.

In cultures of $M$. voltae, the supplementation of $\mathrm{C}_{10}$ suppressed $\mathrm{CH}_{4}$ formation completely and irreversibly after just $8 \mathrm{~h}$ of cultivation (Figure 1, middle). $\mathrm{C}_{14}$ decreased the $\mathrm{CH}_{4}$ formation rate of $M$. voltae by $69 \%$ and $84 \%$ when measured $8 \mathrm{~h}$ and 24 $\mathrm{h}$ after the supplementation, respectively. $\mathrm{CH}_{4}$ formation was delayed when being re-cultured.

The supplementation of $\mathrm{C}_{18}$ had an immediate inhibitory effect on $\mathrm{CH}_{4}$ formation rate $(-58 \%) 4 \mathrm{~h}$ after $\mathrm{C}_{18}$ addition compared to control, but increased again later and no adverse effect on the recovery of M. voltae was observed.

The supplementation of any SFA, that is $\mathrm{C}_{12}$, $\mathrm{C}_{14}$, and $\mathrm{C}_{18}$, almost completely terminated $\mathrm{CH}_{4}$ formation of $M$. thermoautotrophicus within $4 \mathrm{~h}$ after supplementation (Figure 1, bottom). $\mathrm{CH}_{4}$ formation ceased after $8 \mathrm{~h}$ of SFA exposure, except for $\mathrm{C}_{18}$, where $\mathrm{CH}_{4}$ formation still amounted to 2 to $5 \%$ of that of the control treatment. None of the SFA-treated $M$. thermoautotrophicus cultures recovered in SFA-free medium. 

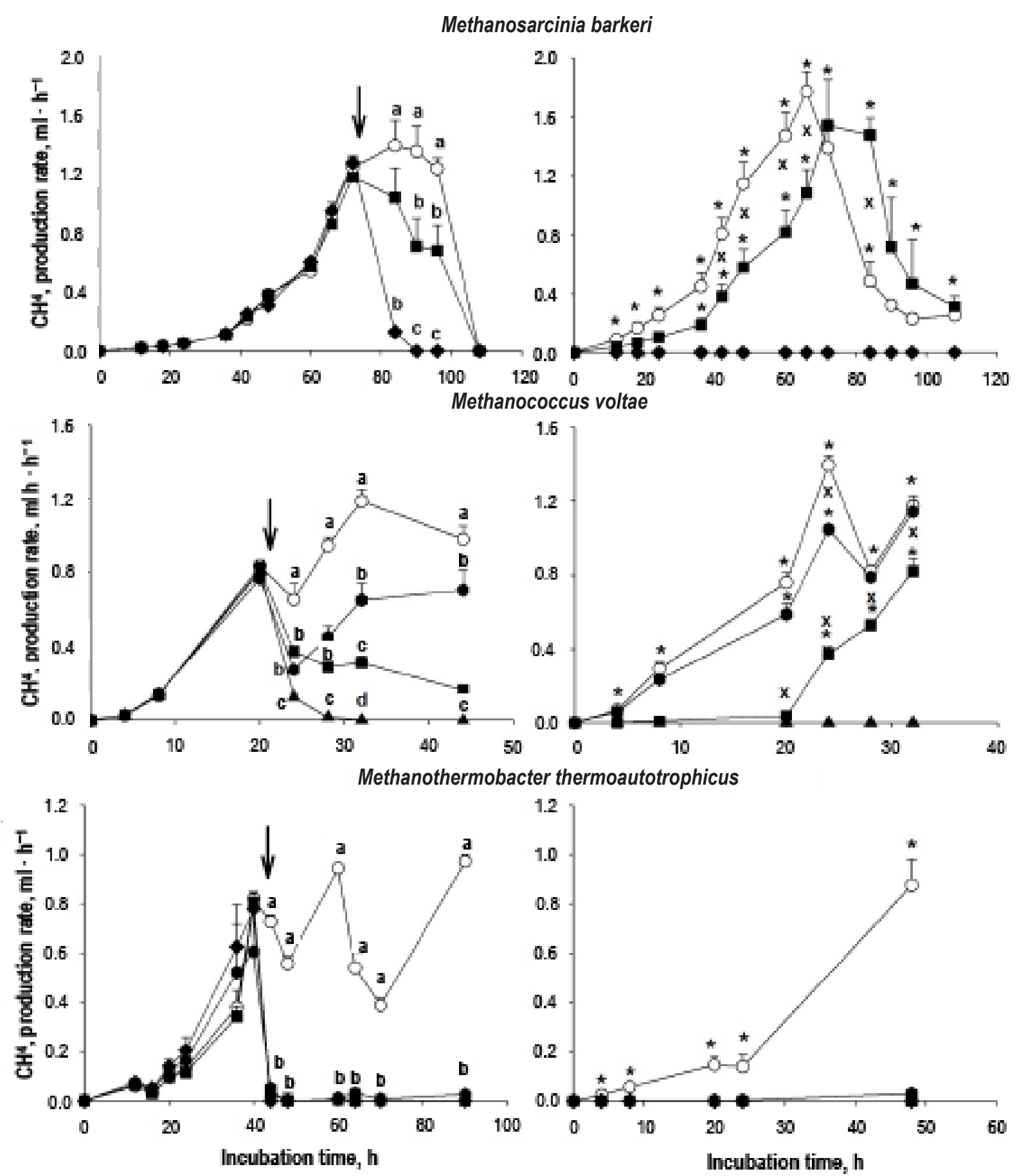

Figure 1. Inhibition of methanogenic Archaea by different fatty acids (left) and their reversibility (right) in Experiment 1. Fatty acids used were $\mathrm{C}_{12}$ and $\mathrm{C}_{14}$ in Methanosarcina barkeri, $\mathrm{C}_{10}, \mathrm{C}_{14}$ and $\mathrm{C}_{18}$ in Methanococcus voltae, and $\mathrm{C}_{12}, \mathrm{C}_{14}$ and $\mathrm{C}_{18}$ in Methanobacterium thermoautotrophicum

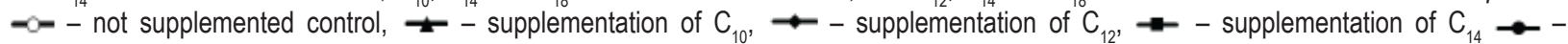
supplementation of $C_{18}, \downarrow$ - time point of fatty acids supplementation. Means with unequal letters $(a, b, c, d)$ are different at $P<0.05$. Asterisks denote means significantly different from 0 at $P<0.05$ (1-sample $t$ test) and $x$ denotes a significant difference $(P<0.05)$ either between control and $\mathrm{C}_{14}$ or between control and $\mathrm{C}_{18}$ (2-sample $\mathrm{t}$ test). Bars represent standard errors

\section{Experiment 2}

Following $\mathrm{C}_{14}$ addition, cultures of $M$. mazei were inhibited by $91 \%$ after $6 \mathrm{~h}$, and completely after $24 \mathrm{~h}$, compared to the control (Figure 2, left) both with and without an excessive amount of HS-CoM. None of the treated M. mazei cultures recovered in $\mathrm{C}_{14}$-free medium. One of the three control cultures
None of the treated M. mazei cultures recovered in C14-free medium. One of the three control cultures showed lower $\mathrm{CH}_{4}$ formation in the recovery period compared to the other control cultures, resulting in high standard errors in this treatment (Figure 2, right), thus preventing the difference to both $\mathrm{C}_{14}$-containing treatments to become significant. 

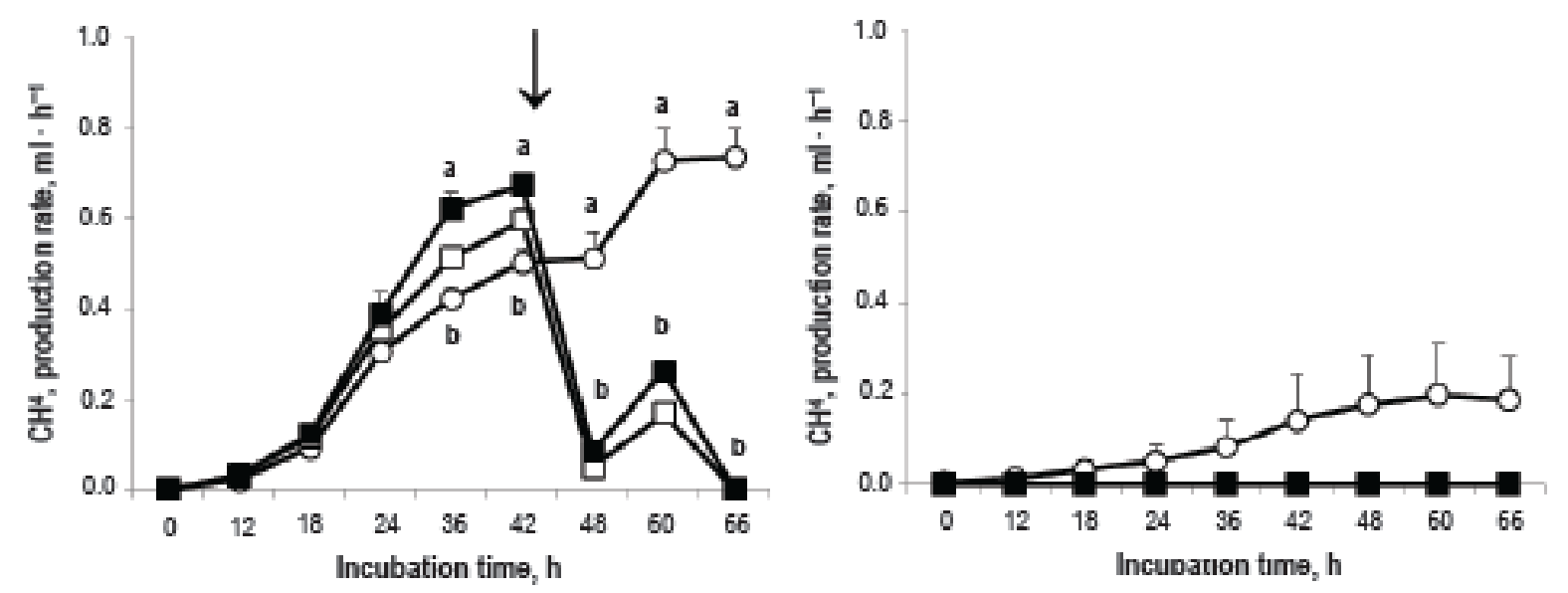

Figure 2. Inhibition of Methanosarcina mazei by $\mathrm{C}_{14}$, either with or without 2-mercaptoethanesulfonic acid (HS-CoM) supplementation (left) and its reversibility (right) in Experiment 2. $-\infty-$ not supplemented control, $\square--$ supplementation of $C_{14},--$ supplementation of $C_{14}$. and $H S-C o M$ $\downarrow$ - time point of supplementation of fatty acids. Means with unequal letters $(a, b, c, d)$ are different at $P<0.05$. Bars represent standard errors

\section{Discussion}

\section{Importance of fatty acid chain length, cultivation temperature and substrate for the anti-methanogenic effect of SFA on the Archaea}

At $37^{\circ} \mathrm{C}$, the anti-methanogenic effect of SFA in methanogenic Archaea decreased with increasing chainlength $\left(\mathrm{C}_{10}=\mathrm{C}_{12}>\mathrm{C}_{14}>\mathrm{C}_{18}\right)$ in the present study. A longer-chain length corresponds to increasing melting temperatures, namely $31,45,58$, and $69^{\circ} \mathrm{C}$ for $\mathrm{C}_{10}, \mathrm{C}_{12}, \mathrm{C}_{14}$, and $\mathrm{C}_{18}$, respectively (Dohme et al., 2000). With increasing melting points the SFA are less well distributed in the cultivation medium at $37^{\circ} \mathrm{C}$. Therefore, fewer cells might have been in contact with $\mathrm{C}_{18}$ as compared to $\mathrm{C}_{14}$ and especially to $\mathrm{C}_{12}$, which would allow the $\mathrm{C}_{18}$-treated cultures to recover faster. It was obvious that recovery was not observed when the SFA had stopped $\mathrm{CH}_{4}$ formation completely thus indicating that cell death occurred. Methane formation during recovery has taken place at a slower velocity in cases where the previous anti-methanogenic effect had been more serious. A higher percentage of dead cells in the inocula from SFA-supplemented cultures might have contributed to this effect; however, cell viability was not tested in the present study. It could not be avoided that small amounts of SFA were carried over with the previously SFA-treated culture. However, then the concentration of SFA is 30 -fold lower, which would not explain the massive delay in $\mathrm{CH}_{4}$ formation found in the recovery period. Although the contact of SFA with the methanogenic cells might be a prerequisite, molten SFA do not necessarily have an adverse effect on methanogenesis. For instance, caprylic acid $\left(\mathrm{C}_{8}\right)$ supplemented to complete diets had no anti-methanogenic effect in ruminal fluid in vitro (Dohme et al., 2001; Abel et al., 2002) even though it is completely molten at $39^{\circ} \mathrm{C}$. The reason for this is unclear. However, when the entire rumen microbial community and complete diets are involved, microbial and substrate interactions are much more complex and other factors of influence might be decisive and could prevent SFA-induced inhibition. It has also been shown that bacteria previously exposed to $\mathrm{C}_{18}$ can get resistant to $\mathrm{C}_{18}$ addition within hours (Laser, 1952), which might contribute to explain the recovery of $M$. voltae cultures exposed to $\mathrm{C}_{18}$.

At $65^{\circ} \mathrm{C}, M$. thermoautotrophicus was clearly and irreversibly inhibited by $\mathrm{C}_{12}, \mathrm{C}_{14}$, and $\mathrm{C}_{18}$. The initiation of the $\mathrm{C}_{18}$-induced effect was slightly retarded compared to that of the other two fatty acids which might reflect that $\mathrm{C}_{18}$ is not completely molten at $65^{\circ} \mathrm{C} . \mathrm{C}_{18}$ was also found to inhibit methanogenesis in cattle manure incubated at $55^{\circ} \mathrm{C}$ (Angelidaki and Ahring, 1992). However, composition and structure of the archaeal cell envelope differ within orders, which may include a response to habitat temperatures (Albers and Meyer, 2011) and result in a different susceptibility of $M$. thermoautotrophicus as compared to the strains grown at $37^{\circ} \mathrm{C}$. It was not possible to successfully cultivate strains of two ruminal methanogens, Methanomicrobium mobile and Methanobrevibacter ruminantium, which were originally part of the study. Therefore, further studies have to demonstrate whether an apparent effect of temperature is really mediated by a different aggregate state of the SFA in ruminal methanogens. 


\section{Potential modes of action regarding the inhibitory effect of the saturated fatty acids}

The cell envelopes, especially the cell membranes, are probable target sites where effects of SFA are expected to occur in a range of microorganisms (Desbois and Smith, 2010). The fatty acids might also directly affect enzymes or other functional features of the methanogenic cell. This has already been proposed for enzymes and transport proteins in bacterial cell membranes (Desbois and Smith, 2010). In the present study, it was tested whether the MCR, a key enzyme in methanogenesis and common to all methanogenic Archaea (Thauer, 1998), is specifically inhibited by SFA, i.e. if an excess of HS-CoM, the coenzyme for the MCR and substrate analogon to SFA, would actively counteract this competition. However, in M. mazei an excessive amount of HS-CoM did not prevent the $\mathrm{CH}_{4}$-mitigating action of $\mathrm{C}_{14}$ at all, suggesting that this is not the reason for the SFA-induced effect on methanogenesis. It still has to be tested if SFA are acting competitively with coenzyme B.

\section{Conclusions}

Knowledge on the mode of action of SFA on methanogens is essential for developing effective and sustainable $\mathrm{CH}_{4}$ mitigation tools, as they are intensively searched for (Hook et al., 2010). The present study demonstrated that $\mathrm{CH}_{4}$ formation from different substrates and in different species of methanogenic Archaea is inhibited by SFA and is dependent on SFA chain length at $37^{\circ} \mathrm{C}$. There are indications that the anti-methanogenic effect of SFA which are not (completely) molten at $37^{\circ} \mathrm{C}$ is increasing with increasing cultivation temperature, but future studies have to exclude that the increasing anti-methanogenic effect of SFA at $65^{\circ} \mathrm{C}$ in cultures of $M$. thermoautotrophicus is due to a specific susceptibility of this strain. Further studies with ruminal methanogens are necessary. The presence of a competitive inhibition of the methyl coenzyme $\mathrm{M}$ reductase by SFA can be excluded with high probability. The mechanism(s) causing $\mathrm{CH}_{4}$ inhibition still awaits identification. This is also true for the reasons underlying the differences found between the methanogenic strains tested. The most promising sites to investigate, and to eventually understand the mode of action of the SFA-induced $\mathrm{CH}_{4}$ mitigation, are the cell envelopes of the Archaea.

\section{References}

Abel H.J., Immig I., and Harman E., 2002. Effect of adding caprylic and capric acid to grass on fermentation characteristics during ensiling and in the artificial rumen system RUSITEC. Anim. Feed. Sci. Tech. 99, 65-72
Albers S.-V., Meyer B.H., 2011. The archaeal cell envelope. Nat. Rev. Microbiol. 9, 414-426

Angelidaki I., Ahring B.K., 1992. Effects of free long-chain fatty acids on thermophilic anaerobic digestion. Appl. Microbiol. Biotechnol. 37, 808-812

Desbois A.P., Smith V.J., 2010. Antibacterial free fatty acids: activities, mechanisms of action and biotechnological potential. Appl. Microbiol. Biotechnol. 85, 1629-1642

Dohme F., Machmüller A., Wasserfallen A., Kreuzer M., 2000. Comparative efficiency of various fats rich in medium-chain fatty acids to suppress ruminal methanogenesis as measured with RUSITEC. Can. J. Anim. Sci. 80, 473-484

Dohme F., Machmüller A., Wasserfallen A., Kreuzer M., 2001. Ruminal methanogenesis as influenced by individual fatty acids supplemented to complete ruminant diets. Lett. Appl. Microbiol. 32, 47-51

Dohme F., Machmüller A., Sutter F., Kreuzer M., 2004. Digestive and metabolic utilization of lauric, myristic and stearic acid in cows, and associated effects on milk fat quality. Arch. Anim. Nutr. 58, 99-116

Goel G., Arvidsson K., Vlaeminck B., Bruggeman G., Deschepper K., Fievez V., 2009. Effects of capric acid on rumen methanogenesis and biohydrogenation of linoleic and a-linolenic acid. Animal 3, 810-816

Hook S.E., Wright A.-D.G., McBride B.W., 2010. Methanogens: methane producers of the rumen and mitigation strategies. Archaea, 10 p. doi: 10.1155/2010/945785

Hovey R., Lentes S., Ehrenreich A., Salmon K., Saba K., Gottschalk G., Gunsalus R.P., Deppenmeier U., 2005. DNA microarray analysis of Methanosarcina mazei Gö1 reveals adaptation to different methanogenic substrates. Mol. Gen. Genomics 273, 225-239

Hristov A.N., Vander Pol M., Agle M., Zaman S., Schneider C., Ndegwa P., Vaddella V.K., Johnson K., Shingfield K.J., Karnati S.K.R., 2009. Effect of lauric acid and coconut oil on ruminal fermentation, digestion, ammonia losses from manure, and milk fatty acid composition in lactating cows. J. Dairy Sci. 92, 5561-5582

Hristov A.N., Lee C., Cassidy T., Long M., Heyler K., Corl B., Forster R., 2011. Effects of lauric and myristic acids on ruminal fermentation, production, and milk fatty acid composition in lactating dairy cows. J. Dairy Sci. 94, 382-395

Koster I.W., Cramer A., 1987. Inhibition of methanogenesis from acetate in granular sludge by long-chain fatty acids. Appl. Environ. Microbiol. 53, 403-409

Laser H., 1952. Adaptation of Bacillus subtilis to fatty acids. Biochem. J. $51,57-62$

Machmüller A., Kreuzer M., 1999. Methane suppression by coconut oil and associated effects on nutrient and energy balance in sheep. Can. J. Anim. Sci. 79, 65-72

Soliva C.R., Hindrichsen I.K., Meile L., Kreuzer M., Machmüller A., 2003. Effects of mixtures of lauric and myristic acid on rumen methanogens and methanogenesis in vitro. Lett. Appl. Microbiol. 37, 35-39

Soliva C.R., Meile L., Hindrichsen I.K., Kreuzer M., Machmüller A., 2004. Myristic acid supports the immediate inhibitory effect of lauric acid on ruminal methanogens and methane release. Anaerobe 10, 269-276

Thauer R.K., 1998. Biochemistry of methanogenesis: a tribute to Marjory Stephenson. Microbiol. SGM 144, 2377-2406

Thauer R.K., Kaster A.-K., Seedorf H., Buckel W., Hedderich R., 2008. Methanogenic archaea: ecologically relevant differences in energy conservation. Nat. Rev. Microbiol. 6, 579-591

Zhang C.M., Guo Y.Q., Yuan Z.P., Wu Y.M., Wang J.K., Liu J.X., Zhu W.Y., 2008. Effect of octadeca carbon fatty acids on microbial fermentation, methanogenesis and microbial flora in vitro. Anim. Feed Sci. Tech. 146, 259-269 